\title{
Implicaciones teatrales \\ en la performance del rap feminista de Gata Cattana
}

\author{
SUSANA PINILLA ALBA Bergische Universität Wuppertal, Alemania \\ ORCID 0000-0003-2255-0153 \\ pinillaalba@uni-wuppertal.de
}

\section{Resumen}

En este trabajo se cuestiona la función de la performance para construir y delimitar la poética del rap feminista. En un primer momento, se expondrán los significados de performance tanto en los vínculos entre la autora y su alter ego en el rap, como en los que mantiene para con su recepción. Nos servirán para este análisis un corpus de cuatro canciones de la artista que se revisarán bajo los preceptos de la retórica y la sociolinguiística desde un enfoque feminista basado en la teoría de la interseccionalidad a fin de delimitar cómo la performance influye en la recepción de la artista. Los resultados apuntan al uso utilitarista del rap para impactar en sus coetáneos, para lo que la artista emplea la politropía. Por una parte, apela a un público joven andaluz con vistas a salvaguardar lo autóctono y la memoria mediante la identificación catártica; por otra parte, articula un discurso para su recepción internacional recurriendo al potencial transformador de sus realidades particulares.

Palabras clave: rap feminista / recepción / performance / Gata Cattana / interseccionalidad

\section{Theatrical implications in the performance of Gata Cattana's feminist rap}

\section{Abstract}

This work questions the role of performance in building and delimiting the poetics of feminist rap. Initially, the meanings of performance will be presented, both in terms of the links between the author and her rap alter ego, and in terms of the links she maintains with her reception. A corpus of four songs by the artist will be used for this analysis, which will be reviewed under the precepts of rhetoric and sociolinguistics from a feminist approach based on the theory of intersectionality in order to delimit how performance influences the artist's reception. The results point to the utilitarian use of rap to impact on her contemporaries, for which the artist employs politropia. On the one hand, she appeals to a young Andalusian audience with a view to safeguarding what is autochthonous and the memory through cathartic identification; on the other hand, she articulates a discourse for its international reception by resorting to the transformative potential of its specific realities.

Key words: feminist rap / reception / performance / Gata Cattana / intersectionality

Recibido: 7/12/2020. Aceptado: 3/3/2021

Para citar este artículo: Pinilla Alba, S. (2021). Implicaciones teatrales en la performance del rap feminista de Gata Cattana. El taco en la brea, (13) (diciembre-mayo). Santa Fe, Argentina: UNL. eoo32 DOI: 10.14409/tb.v1i13.10225 


\section{Contexto sociocultural del rap en España}

El rap nace como expresión artística de protesta y descontento ante la abrumadora precariedad y marginación de la comunidad afroamericana y latina de la periferia neoyorquina (Price-Styles, 2015; Camargo, 2007; Corral Rodríguez, 2014-2015) de la mano de individuos desposeídos de derechos y sin expectativas que se agruparán en torno a las manifestaciones artísticas del hip hop a fin de expresar su descontento y exigir mejores condiciones de vida (Reyes, 2007; Chang, 2007). La presencia del hip hop en distintas artes como la música (competencia del DJ y del MC), el baile urbano (breakdance) y la pintura mural (graffiti) dotará de multidimensionalidad a la representación cultural de este malestar. Esta cultura se asentará en España pasando por distintos procesos de recepción, desde la venta masiva hasta el ostracismo. A principios de los 90 se irá fraguando un proto-rap español con esencia propia, que ya entonces ofrecía potencial creativo debido a la maleabilidad de la estructura silábica del español (en comparación con el inglés), lo que permitía sustanciosos juegos retóricos y fonéticos; así como por la naturaleza del ideario social y cultural del país, ajeno al de los guetos estadounidenses.

Las diferencias socioculturales entre el norte y el sur, así como la distancia territorial de sus centros, darán lugar a dos escenas grosso modo en las que destacará una producción más existencial y poética (en el norte, con foco en Zaragoza y Madrid), cultivada por raperos de clase media con fuerte compromiso social; frente a la producción del sur, con tendencias al rap gangsta cuyos autores procedían de las zonas más humildes de las metrópolis andaluzas. Esta diferenciación entre las escenas, si bien en nuestros días se encuentra igualada gracias a la existencia de subvenciones para los estudios superiores en lo que respecta a temas y tratamiento formal de los mismos, conservó la autenticidad y fidelidad a sus orígenes a través de la preeminencia de la jerga juvenil y el acento como rasgo cultural identitario (en el caso de la escena del sur). Algunas figuras destacables en estos territorios, como por ejemplo Kase.O en Zaragoza o Zatu en Sevilla crearon escuela alrededor de sus ciudades, situándolas como centros fundamentales para el rap español old school. Sobre estas escenas se reconvertirá el panorama distinguiendo entre los veteranos y el rap del nuevo milenio, una new school influida de los movimientos culturales y sociales del momento, donde situamos sin duda al rap feminista.

En este turbulento momento social, la implosión del ciberfeminismo posibilitó la comunicación entre todos aquellos feminismos desplazados del núcleo, sin respaldo de las élites, que vieron en su alianza una forma de prosperar en la retaguardia. A estos movimientos políticos, sociales y económicos contrahegemónicos (siendo los más fructíferos para el rap el ecofeminismo y el feminismo decolonial) se sumaron las vindicaciones sociales que ya existían en el rap convencional, como el anticapitalismo y la protesta ante el abuso de autoridad. Todas ellas serán el caldo de cultivo del fenómeno que eclosionó a partir del 2010, una ola de rap feminista a nivel panhispánico respaldada por la sororidad de productoras, autoras y público, gracias al apoyo en las redes sociales y a su expansión también en contextos ajenos al hip hop, llegando a introducirse incluso en los círculos culturales y educativos más canónicos.

La crisis económica de 2008 y las vindicaciones feministas de cuarta ola, junto con la extensa difusión de músicas como el trap — término paraguas que actualmente parece vacío de significado-, darán lugar a un panorama cultural en el que autores y consumidores compartirán protagonismo, por una parte, con la generación más fiel al rap de los inicios, procedente de la escuela old school de rap (los maestros o padres del rap español); y por otra, con una escuela 
posterior que rompe los paradigmas del género empleando el feminismo como enfoque e intención predominante en su obra. Es en este contexto de transición en el que podemos ubicar la producción musical de la rapera Gata Cattana, figura prometedora del rap español, que comenzó su carrera musical en 2013 con el EP Los siete contra Tebas y concluyó la misma con su LP póstumo: Banzai (2017). En su legado podemos ver los cimientos de un género de rap que está remodelando la escena del hip hop internacional, tanto en lo que respecta a la performance de las autoras, como a la recepción de las mismas.

\section{Rap feminista y performatividad}

En el campo filológico, la mayoría de los estudios se centra en los aspectos poéticos de este género (Martínez Cantón, 2010; Buscató Vásquez, 2016), descuidando otras dimensiones del mismo como la narratológica o la teatral. El género literario del que más se nutre el rap a la hora de experimentar con su performance es el teatro, de ahí que sus aportaciones sean significativas e influyentes para su recepción. La performance de estas artistas escenifica el empoderamiento de la mujer a través del arte, que mediante una intención social funciona como catalizador de contenidos políticos. La artista se convierte en una oradora pública, cuyo ethos y actitud sobre el escenario constituirán los pilares sobre los que construya su performance. El auge del rap feminista es un caso más de la conquista que las mujeres están haciendo de los espacios vetados para ellas: enunciar desde el rap resignifica el género del hip hop al poner en cuestionamiento sus fundamentos y al aportar un enfoque feminista a su poética. La introducción de temas que preocupan al feminismo y la innovación formal y conceptual de sus mecanismos, así como la inversión de mujer-objeto a mujer-sujeto, dotarán de interés a este discurso para los estudios de género, pero también serán decisivos para su análisis literario. La performance de estas autoras se convierte entonces en la escenificación consciente de la toma de este espacio, que encuentra en la manifestación artística de su reivindicación vocal y corporal la superación de las violencias a las que son sometidas las comunidades a las que representan.

La noción de performance en el rap se halla en un punto en común entre la ficcionalidad y la factualidad de su discurso. Por una parte, el rap en su dimensión artística emplea elementos literarios para construir su mensaje y para proyectarse en el escenario. Por otra parte, los rasgos factuales presentes en las referencias históricas y actuales que emplea, así como en el uso de ideologemas ${ }^{1}$ que vertebran críticamente el discurso, complejizan la separación de la autora del personaje. El cruce de la literatura (terreno de ficción) junto con la oratoria (terreno de la realidad) se manifiesta en el rap a través de un uso similar de elementos retóricos y tópicos literarios con fines persuasivos. Además, las exigencias de la recepción del rap difieren de las que se puedan pretender con la literatura ficcional, llegando a ser similares a las expectativas proyectadas sobre la poesía social o el teatro épico. El rap como discurso híbrido, tanto por su multidisciplinariedad (música, letra y performance) como por su mezcolanza de niveles epistemológicos (realidad y ficción), se nutre de estos saberes tradicionales adaptándolos a los contextos en los que surge. ${ }^{2}$

Las corrientes menos conformes con el feminismo hegemónico encontrarán en el rap un aliado poderoso para la demolición de los discursos que las excluyen, pero también les será de utilidad para influir estéticamente en las líneas de pensamiento y temáticas del género en sí. ${ }^{3} \mathrm{~A}$ este propósito, un rap feminista opuesto a los propios parámetros del rap representa en nuestro imaginario un discurso contracultural de resistencia teñido de implicaciones políticas, con 
el fin de desmontar retóricamente los discursos de odio (van Dijk, 1999). Los preceptos de una poética del rap fruto de la interacción de elementos clásicos como la credibilidad ligada a la posición de autoridad ocupada por el artista, el ingenio en la disposición formal, su consecuente innovación estilística y la exaltación del ego fomentada a través del impacto en la recepción se reactivarán en el rap feminista combinando ambos objetivos: el social y el cultural. Este acercamiento textual al rap nos permite reflexionar sobre la «acción» que los textos del rap provocan en los sujetos que enuncian y en su recepción. De este modo, el desempeño (rendimiento) de la rapera se vincula a nivel del logos con la calidad de su trabajo, característica intrínseca del rap: la exaltación de la habilidad retórica de la rapera, lo que a la vez refuerza el ethos (su autoimagen y la imagen que proyecta en los demás, pero al mismo tiempo su aptitud moral e ideológica) a través de un ars rethorica en el que se mezclan procedimientos argumentales para impactar en la recepción, ya sea por medio de la razón (logos), en su interpelación al público internacional; o del sentimiento y la emoción (pathos), vías para la conexión con un público más autóctono.

A la luz de esta definición, la performance del rap conciencia, subgénero al que pertenece el rap feminista, ocurre en un nivel ficcional que se nutre y retroalimenta temáticamente de los sucesos de actualidad y de la situación real que esté experimentando la autora. Por ello, pese a que se trata de un texto literario, su relación con la realidad debe estar presente para generar legitimidad, característica imprescindible en el rap, de ahí que estas producciones estén siendo consideradas dentro de lo que algunos autores como R. Keelly han denominado «poéticas da luta e da experiência vivida» (en Salgado, 2015), es decir, espacios de resistencia por las condiciones de producción, pero también por la temática y la subalternidad de los sujetos que las producen.

Mediante la aplicación de estos preceptos retóricos al rap nos interesa especialmente analizar dos interpretaciones del término performance. Por una parte, algunos autores la han entendido como «acción» ${ }^{4}$ (Hodges Persley, 2015; Kautny, 2015; Price-Styles, 2015; Ramírez Torres, 2017), insistiendo en el carácter utilitarista ${ }^{5}$ de la noción de «rendimiento» que Ramírez Torres definía como «tener un buen desempeño», o bien, mostrar calidad en la realización de una actividad, lo que implica concebir la performance como imagen social y estética que la autora proyecta en el auditorio, es decir, lo que marca su estilo y determina su éxito: su flow. ${ }^{6}$ Sin embargo, otra noción de performance que vendría a complementar a la anterior más que a excluirla, reside en su consideración como vehículo para conmocionar al público a través del desarrollo de una idea o recurso estilístico, es decir, no conlleva necesariamente un correlato factual, por lo que, en este sentido, funcionaría como «fictio» o como «mímesis» (simulación o «engaño»): aquello que representa lo real sin llegar a serlo, gracias al recurso de la verosimilitud, es decir, una representación o imitación de la realidad que permita explorar soluciones o vías alternativas a las que existen en un plano real. Esta visión justificaría la existencia de un arte comprometido, cuyas notorias implicaciones en la realidad aportan «verdad» al discurso ficcional valiéndose de los recursos de ambos planos para fomentar una participación activa del público en su propia historia.

El carácter ficcional del rap permite desdoblar el autor del personaje, para ello emplea la performatividad para proyectar la rabia ante la discriminación y lograr canalizar la pulsión feminista mediante actitudes y puestas en escena que no son posibles desde una plataforma política o ensayística. Defender una idea de forma artística conlleva dar rienda suelta a la libertad creativa con artificios socialmente censurables para desmontar discursos del odio, es decir, el uso de la violencia, la agresividad, la irreverencia o la escatología son permisibles sin demasiados 
miramientos por una recepción que no los toleraría fuera de un universo artístico. Gracias a esto podemos explicar performances de rap feminista desde la violencia, como los videoclips de grupos como Ira, La Furia o Machete en boca en España, respuestas que en un plano de la realidad resultarían paradójicas, teniendo en cuenta que la intencionalidad del rap feminista es acabar con la violencia machista y con las discriminaciones interseccionales.

\section{El rap como ceremonia: la ritualización del feminismo a través de la acción}

El rap (recitación sobre una base rítmica) como performance oral que queda para la posteridad en forma de grabación es obra de dos integrantes como mínimo: el DJ y el MC (master of ceremony). Las raperas emplean su ejecución sobre el escenario (en los conciertos), o su desempeño en las entrevistas para proyectar una imagen de MC con la que construyen y fundamentan su reputación y actúan como representantes de una comunidad más amplia (en el caso del rap feminista). La representación pública del MC es la base sólida sobre la que se sustenta el ethos de la rapera, por tanto, el cuidado de la imagen que se pretenda proyectar en el público será decisiva en la interpretación artística de la performance. La autodeterrminación que debe reflejar la artista sobre el escenario es aquella que le confiere la autoría de sus propias letras basadas en elementos factuales para reforzar su credibilidad en la escena a la que pertenezca.

La rapera debe convertirse en la maestra de ceremonias (MC), entendiendo que la puesta en escena del rap supone «la ceremonia» y que la autora, por tanto, se halla en la labor de dirigirla y utilizar este acto para lograr el favor del público (captatio benevolentiae). Esta noción de "ceremonia» dista mucho del evento religioso y aunque solo en parte está ritualizado (por ejemplo, en las «batallas de gallos» se siguen pautas de actuación muy concretas), 7 depende en gran medida del artista $^{8}$ en concreto y de su estilo. Varios raperos coinciden en el carácter sublime del MC, como el rapero que se sitúa en un estadio superior, ya que mediante su performance establece una conexión real con el público (El Chojín, 2020), mientras que el rapper (rapeador sin performance) no lo logra. La figura del MC, por tanto, es la máxima aspiración del rapero por su habilidad para trazar vínculos entre la dimensión discursiva de su oratoria, su puesta en escena (performance corporal y vocal) y entre las expectativas de su recepción.

La ceremonia en el rap entra en el campo del drama social y de la enunciación narrativa, similar a la recitación épica (el narrador recita sus gestas —o las de otros-, sentimientos o peticiones sociales ante un público que disfruta de esa ficción), pero su puesta en escena es muy variada (desde una batalla bien acotada por la estructura y duración de las intervenciones de los participantes, hasta una representación ficcional que fusione rap con publicidad, cine, coreografía...). Los límites de la puesta en escena son inmensurables, sin embargo, observamos el componente performativo en el juego de alter-egos que se establece en la enunciación de la autora a través del rap y de la poesía, puesto que son difusos los límites entre estos géneros y el slam poetry. El desdoblamiento del yo poético de la autora construye distintos ethos en comunión con el propósito de la plataforma que emplee para enunciar. Así pues, Ana Isabel García Llorente se decantará por un ethos más existencial y estético en su identificación como poeta, para la que empleaba el seudónimo de Ana Sforza, mientras que empleará un tono más agresivo y directo al proyectarse en una faceta más hardcore y socialmente comprometida a través del rap, bajo el apelativo de Gata Cattana. ${ }^{9}$ Estos recursos de ficcionalidad señalan un alejamiento de la performance del rap respecto a la realidad: la creación de un personaje (alter-ego) sobre el que proyectar su obra para 
desvincularse del yo creativo de la autora contribuye a canalizar un sentir colectivo o ideologema de forma más pura, es decir, la rapera puede erigirse de este modo como representante de una colectividad, más allá de la idiosincrasia personal de autora, Ana Isabel García.

La performance es también el medio de comunicación de la experiencia, que es a su vez la expresión materializada de la tradición del saber acumulado en las obras de arte y en la memoria popular, es decir, es la tradición de la communitas que se expresa en el rap gracias a su carácter ideológico, como «a play that is about a maturing hip hop generation and how it is desperately struggling with contradictions, politics, identity, sense of responsability and what community means» (Hodges Persley, 2015:94). En este sentido, si la posibilidad del rap permite desentrañar el significado de la comunidad o los pilares sobre los que se sustenta, las raperas funcionan como representantes de la misma, de forma que su voz encuentra una amplia recepción en los rasgos compartidos. La dramaturga Lola Blasco señalaba las concomitancias entre la función social y ritualizada del coro clásico y la del rapero, entendido este en su alter-ego ficcional:

Actualizar la figura del clásico rapsoda respondía a mi deseo, por aquel entonces, de volver al rito, al origen del propio teatro. Era también una forma de lamento hacia las víctimas. Si convertí al coro en un coro de rap fue porque me pareció que era equivalente. Yo pensé en el coro griego, y con cómo cantaba las injusticias de su época y me pregunté ¿Quién hace eso hoy en día? Y la respuesta fue: el rapero. No en vano la palabra rap proviene de rapsoda. El rapero es el poeta de la calle, del pueblo, un poeta que canta las injusticias contemporáneas que todos conocemos. El rapero no descubre nada nuevo, simplemente enuncia lo que todos sienten para compartir el dolor. (en Romera Castillo, 2016:47)

El goce estético se produce a través de una aceptación del «juicio impuesto» por la obra o de las «normas de conducta» prescritas por la misma (Estébanez Calderón, 2001) que encuentra su correlación en el sentir colectivo. El discurso subversivo del rap feminista desafía los esquemas de valores internos del rap convencional, desviándose del «oyente ideal» (varón heterosexual). La teatralidad del rap, en su representación de coro, ${ }^{10}$ aparece para Blasco ligada a una función folclórica que hunde sus raíces en la tradición y costumbres del pueblo, pero también con contenido político, como representante de los intereses y bienestar del mismo. Esta voz coral nos recuerda a la voz comunal de Susan Lanser y a la figura del subalterno empoderado de Spivak como materialización de una colectividad capaz de enunciar por medio de la rapera. Así pues, la enunciación del artista no es fruto de su propia autodeterminación, sino que nace de la reivindicación conjunta, de la denuncia para una igualdad que traspase las fronteras de lo individual. Por otra parte, utilizar el rap para Blasco parece ser volver a un teatro original cuyo fundamento se hallaba en el valor del ritual, aspecto que parece indispensable para construir una conciencia común que no reprima la memoria colectiva, pero que continúe teniendo vigencia actual.

El valor de la comunidad se expresa a través de la performance vocal y lingüística gracias a la capacidad de la literatura para proponer modelos alternativos de mundo y a la capacidad lingüística para otorgarle fuerza realizativa. A propósito de la concepción del rap, interesa indagar sobre el carácter repetitivo que construye ritual y que se manifiesta en el rap a través del beat (una secuencia de sonidos rítmica y reiterativa, generalmente en 4x4) que aporta un determinado ritmo poético. La autora debe adecuar el tempo de su dicción al ritmo del beat y el público adopta el mensaje a través de los golpes de compás que acompaña con movimientos de cabeza 
semejantes a un asentimiento. ${ }^{11}$ En este sentido, el beat otorga al rap un elemento reiterativo que funciona de intermediario entre la rapera y el auditorio. Hasta el punto de que la elección del beat redirige la recepción, ya sea pretendiendo interpelar a un público a través de una vía más emocional, como observamos en el empleo de músicas étnicas y regionales como el flamenco (véase «La prueba» - 2015-); o bien, conmover a una recepción joven a través de ritmos más actuales como el trap, ${ }^{12}$ como observamos en algunos temas del LP Banzai (2017), o en canciones anteriores como «Yerma» (2016). Mientras que las primeras canciones muestran un beat old school (véase «Rayos»-2016-), más próximo a las tendencias de principios del milenio, momento en el que la artista trabajaba también con productores en Andalucía, sus últimos temas presentan elementos más afines a los estilos y expectativas de las generaciones más jóvenes.

La concepción de performance como «acción» también se refleja a través de la noción de performance lingüística que Austin puntualizaba mediante la fuerza realizativa de las palabras, es decir, ir más allá del significante para cambiar el significado. Al conducir el mensaje a una categoría física, no solo cognoscitiva, se produce un cambio de paradigma en el imaginario colectivo que llevará consigo un cambio de valores y actuaciones en el habitus del auditorio. Estos «enunciados performativos» se construyen a sí mismos en su ejecución vocal y encabezan acciones en su propia articulación, por lo que empoderan a los actantes que los pronuncian impactando así en su recepción a través del sociolecto. Un ejemplo destacable de ello aparece en el verso: «Yo os invoco, hijas de Eva, buscando una luz...» ("Lisístrata», 2015).". Observamos el uso del verbo realizativo «invocar» como una llamada ritualizada que trae a la memoria a las antepasadas condenadas por el poder patriarcal y religioso. Sin embargo, el verbo «invocar» añade una connotación espiritual más allá del estado físico de la materia, por lo que alude en cierto modo a una experiencia paranormal. Por otra parte, en la misma canción se menciona: «Un tributo a mis musas, que luchan», es decir, un homenaje que implica el uso del sustantivo «tributo» en mención de las mujeres ejemplares para ella: mujeres subversivas que desafiaron los códigos de valores dejando una huella en la historia, pese a que esta haya sido ocultada en múltiples ocasiones. El acto de memoria no anhela visibilizar simplemente a las mujeres silenciadas, sino que pretende la reparación del daño, la venganza de siglos de opresión. Un ejemplo de cómo este discurso ficcional cambia la realidad factual aparece en la recepción que un sector del feminismo llevó a cabo a partir de la creación del proyecto («Radiojaputa») autofinanciado por las oyentes, cuya sección de intercambio entre las mismas titularon «Aquelarre» ${ }^{14}$ en una suerte de invocación a las sucesoras de esas brujas que reivindican su legado de rebeldía y desacatamiento de las normas sociales. La canción «Lisístrata» es la melodía introductoria que se repite en cada una de las emisiones del podcast como símbolo del apoyo del feedback que las mismas oyentes ofrecen a sus camaradas.

Gata Cattana expresa abiertamente dicho propósito de «pasar a la acción» en muchas de sus letras, como observamos en «El plan» (2017): «Estaba ahí con mis negritos echándole sazón, trayendo la nueva esperanza a mi generación/ hoy soy purita subversión, tú ponme un plan, yo pongo el avión», donde manifiesta que ella es el conducto o medio por el que su comunidad puede hablar, e incluso llevar a cabo «un plan» mayor, una revuelta feminista de la que ella solo es una mínima parte.

La interacción entre la territorialidad y la exaltación de la habilidad retórica son dos características indispensables que configuran la noción de credibilidad ${ }^{15}$ dentro del rap, siendo esta entendida como la autenticidad con la que se proyecta la imagen de la autora como representante 
digno de la cultura hip hop. En este sentido, en el rap feminista la elección y combinación de expresiones realizativas no solo tiene un fin constatativo sino el de dar voz y visibilidad a un grupo oprimido para transformar sus realidades de opresión. De modo que entran en consideración factores sociolingüísticos que pretenden proyectar una determinada imagen de la autora, que dé legitimidad a su discurso en su crew, así los ideologemas y estilemas que emplea Gata Cattana en la canción «Lisístrata» ${ }^{16}$ dirigen la recepción a un público joven, culto, y en muchos casos, perteneciente a una variedad dialectal del sur de España. La credibilidad de su discurso se refuerza por el cruce que se da en las intersecciones activas de la autora en el proceso de creación: sus rasgos identitarios (mujer andaluza) y contextuales (joven desplazada por el éxodo rural a los centros de riqueza del país). Así pues, el rap feminista no solo actúa contra el sistema patriarcal capitalista a través del cuestionamiento simbólico y conceptual de sus preceptos, sino que se articula lingüísticamente revalorizando y dignificando los modos de hablar desprestigiados, marginados dentro del capital cultural.

\section{Politropía feminista en la recepción de Gata Cattana}

El contenido performativo del rap está bastante ligado a la teoría de recepción de una obra de arte, puesto que es a través de su manifestación como esta se abre espacio entre el público originando diversas actuaciones, entre las que se encuentra la aceptación, la repulsión o la indiferencia, dependiendo del colectivo y del individuo concreto, pues como decía Escapit, «todo escritor es prisionero de la ideología (Weltanschauung) de su público medio-social: puede aceptarla, modificarla, rehusarla total o parcialmente, pero no puede escapar de ella» (en Estébanez Calderón, 2001:887). El rap feminista no "crea» un narratario extradigético nuevo, ausente hasta ahora en la recepción, sino que da visibilidad a un auditorio que, aunque mucho menor en número y medios para pronunciarse, siempre existió. La rapera ocupa una posición marginal dentro del núcleo cultural del hip hop, dominado en un principio por la corriente mainstream «old school» (cuya vertiente conciencia representa a la resistencia contracultural del rap), eje de las producciones de hip hop en España hasta hace aproximadamente una década.

La puesta en escena es la característica del rap que lo aleja de la poesía y lo vincula al lenguaje fílmico estableciendo interesantes analogías con el teatro. Presentar el rap feminista desde la dramaturgia nos obliga a elegir consideraciones sobre el mismo en las que la voz narradora tenga un papel predominante, además de asegurar un impacto en la recepción a través del compromiso social compartido. Esta retórica contribuye al cambio social desde la estructura política del discurso del rap. Por ello nos parece apropiado hablar de un teatro épico que rompe la catarsis en el tipo de mensaje y en los vínculos de no-identificación o de identificación solo parcial que se dan entre sus oyentes. Las semejanzas entre el teatro y el rap en lo que respecta a su performance, el contenido feminista como elemento catalizador del descontento de una comunidad y como punto en común entre la autora y su recepción establecen sugerentes hipótesis acerca de cómo se desarrolla el consumo del rap por parte de los distintos públicos a los que interpela la autora. Así pues, en función del posicionamiento ideológico e identitario del auditorio encontraremos dos acercamientos. En primera instancia desde la catarsis, posible al compartir rasgos identitarios y contextos sociales, lo que facilita una identificación con el personaje, añadiendo a la poética de su obra una dimensión feminista más particular, como podemos observar en la lectura que hacen de ella las mujeres exiliadas de Andalucía. En segundo lugar, la proyección 
internacionalista se conseguiría a través de un efecto de distanciamiento (Verfremdungseffekt), capaz de separar al receptor como individuo de la ideología e intención de la rapera, que expone al personaje, más allá de interpretarlo con fidelidad. ${ }^{17}$

\section{Funciones catárticas y feminismo andaluz}

El empleo de la catarsis en el rap feminista ha experimentado algunos cambios. En el rap actual es anecdótico encontrar representaciones de la mujer como víctima desvalida del patriarcado, como sí ocurría en el rap mainstream cuando se abordaban temas como la violencia machista, apelando así a la «piedad» como vía para lograr la catarsis (ejemplos de ello son las canciones «El final del cuento de hadas» (2005) de El Chojín y «Nanai» (2007) de Mala Rodríguez). A partir del boom feminista encontraremos una inversión de esta dicotomía, de forma que la mujer se convertirá en victimario capaz de infligir la misma violencia en sus opresores. También se apela al «temor» para producir así una catarsis que haga más terapéutica la superación del trauma. Las canciones que tematizan el abuso sexual suelen emplear esta técnica. La catarsis, sin embargo, aparece en la obra de Gata Cattana ligada al aspecto étnico. Así pues, encontramos tantas recepciones como intersecciones se vean cruzadas en la canción, que parten del «conocimiento situado» (Haraway, 1991) de la propia autora.

Por ello, una recepción basada en la identificación a través de la catarsis solo será posible en una atmósfera cuyos contextos y realidades sean compartidas por la autora y las oyentes. Un rasgo elemental para la identificación interseccional se produce a través del uso lingüístico. En el caso de Gata Cattana, el rapeo en dialecto andaluz y la mezcolanza de registros apelan a un determinado sector de la recepción. Los usos lingüísticos en su rap desafían las normas lingüísticas hegemónicas por el uso de la variedad diatópica estigmatizada: ${ }^{18}$ pero también las normas internas del rap, ya que este prefiere una desviación consciente de las variedades diafásicas normativas. Lejos de emplear una jerga callejera y suburbial como acostumbran a hacer los raperos, Gata no esconde sus orígenes rurales y su faceta intelectual y teórica desde la que construye su discurso; de forma que esta dicción la aleja de los círculos de hip hop al mismo tiempo que la acerca a los ambientes universitarios y académicos siguiendo la escuela iniciada por Nach, ${ }^{19}$ férreo defensor del rap poético de gran calidad literaria.

Mientras que los registros empleados son diversos incluso en una misma canción, destacan los arcaísmos y localismos cuando busca conectar con su recepción andaluza procedente del medio rural, como pone de manifiesto el estribillo del sencillo «Yerma» (2016): «Y ahora, solo sé de’onde vengo (...) aceitunita del Almanjáyar, mis chascarrillos de agüita clara, escalofríos $p a$ ' mi serrana». Al margen de la interpretación universalista de su obra, nos interesa para la construcción de los feminismos étnicos la cuestión de cómo se logra identificación con parte del auditorio que comparte estas intersecciones. La conexión lingüística parece ser determinante para acceder a una recepción andaluza rural, mientras que la jerga callejera busca la atención de un público joven, generalmente expatriado debido al éxodo rural y al desempleo de la región, quienes se incluyen como «camaradas» dentro de una misma lectura generacional: el acceso a la cultura y los medios tecnológicos, pero paralelamente, el apego a las costumbres y tradiciones a pesar de su deconstrucción racional, presenta coincidencias afectivas entre la autora y el público. Así pues, pese a una interpretación universalista que consolidará a la artista como emblema universal del feminismo, su obra apela mediante procesos catárticos a otra recepción 
minoritaria, étnica, en la que los procesos de identificación gracias al dialecto compartido y la posibilidad y la construcción de memoria fruto de un mismo sentir comunitario generan goces artísticos desde el cuerpo, la empatía y los afectos no racionales, que conectan con las intuiciones, emociones y formas de sentir y pensarse desde los ejes que se cruzan en la autora (género, etnia y exilio).

\section{Funciones sociales y universalidad}

El rap feminista se dirige a una recepción de la era tecnológica, un público distinto a la generación que lo acogió a su llegada a España. En un contexto donde prima la fusión de ritmos, el versionado y lo que gran parte de los artistas consideran como «apropiación cultural», el rap feminista significa un rasgo de autenticidad en la escena musical actual, en la que este estilo parece ser el predilecto para exponer contenidos políticos, por ello no es sorprendente que sea el discurso musical por excelencia que está construyendo ideología. ${ }^{20}$ La autora se separa del personaje de la rapera como mujer, pero exige a su recepción un compromiso político. El empoderamiento se convierte en una cuestión social conjunta, más allá de la potencialidad individual, de manera que la rapera se debe desvincular de sus sentimientos propios para pasar a ser la voz de una colectividad (Spivak, 2009). En esta coyuntura resultan más factibles las afinidades del rap con el teatro épico; siendo entendido este, por una parte, en su concepción primigenia como teatro narrado, en el que los personajes exponen los hechos a los que se refieren, y cuya representación no tiene un propósito catártico; pero también en su faceta comprometida con la causa feminista, en tanto que ambiciona la toma de conciencia y el cambio social. Por ello, no es de extrañar que estos discursos formen parte de lo que se conoce como rap conciencia, en su alarde de influir ideológicamente al auditorio. El representante de la colectividad que era en la Antigüedad clásica el coro, como intérprete premonitor de la acción se materializa en la performance de la rapera a través de su función mediadora de la soberanía de su comunidad, lo que contribuye a generar en el auditorio el efecto de distanciamiento o extrañamiento, tal y como lo entendía B. Brecht, es decir, la sustitución de la estructura mimética o representativa de los acontecimientos por una exposición de los mismos, obligando al público a forjarse una idea de aquello que está presenciando (en nuestro caso, escuchando).

El hecho de que la rapera se erija como lideresa de una comunidad de mujeres a través de su discurso implica su aceptación como representante, actualizando presupuestos vigentes ya en una segunda ola, cuna del movimiento feminista radical donde se transgredieron los límites de lo individual con la conocida cita "Lo personal es político» (Millet, 1970). El rap se convierte en un canto a la existencia de una comunidad numerosa de «mujeres» consciente de sus diferencias, pero no por ello debilitada sino más unida y comprometida que nunca gracias al uso tecnológico, la cofinanciación a través del crowdfunding, la rapidez y cómoda difusión que ha determinado la forma en la que consumimos arte o el apoyo colectivo que brindan las asociaciones y las personas concretas en los casos de injusticia patriarcal, borrando las fronteras de lo personal e individual. El concepto de autoría se dispersa difuminándose entre lo ficcional y lo factual de los rasgos discursivos del rap. La rapera en su individualidad es la voz de una comunidad, una voz inmensamente política y filosófica porque no habla desde el yo artístico sino desde una pulsión feminista. Un modo de tomar distancia y producir feminismo interseccional y universal que rompe con las concepciones maniqueas de la sociedad y con los grandes temas trágicos, al 
ponerlos en cuestión, desmantelando un sistema que bebe en la tradición cultural hegemónica desde el que somos conscientes que seguimos construyendo conocimiento.

Walter Benjamin definía así el giro social en el teatro que protagonizó la escuela de B. Brecht: «La escena está todavía elevada, pero ya no emerge de una hondura inconmensurable; se ha convertido en una plataforma pública. Sobre esta plataforma tiene que instalarse ahora el teatro» (Benjamin, 1975:17). Volviendo a la comparación entre el coro clásico y el rap conciencia, este cambio de paradigma artístico incumbe al rap en tanto que representa todas las funciones del coro griego, al mismo tiempo que las resignifica. La opinión de índole antropológica que defiende el coro no pertenece al sistema hegemónico de valores, sino a una producción contracultural que atenta contra el constructo simbólico imperante. Un rap que retoma la función sublime del coro clásico encarnándose en una subalterna resulta un atentado contra el sistema de valores. Cuando su recepción crece a ritmo exponencial, podríamos interpretarlo como una fisura en el sistema, es decir, se vislumbra una esperanza a través del arte para lograr un cambio socioeconómico.

Los paralelismos entre el surgimiento de este teatro y el rap feminista encuentran motivos similares. Por una parte, el ostracismo y la devaluación de la obra que muchas escritoras han experimentado tiene su correlación en el mundo del rap, puesto que también existía ese "techo de cristal» para las autoras que accedían a la escena travistiéndose en muchas ocasiones para parecerse a los hombres, pues casaban mejor con las características convencionales de este género (competición, individualismo, exaltación del ego, etc.). Por otra parte, el sustrato creativo para el rap español tras la crisis de 2008 obliga a un cambio de paradigma al que las raperas contemplan su devenir tragicómico sin grandeza en la representación. Un rap poético o melódico que suscite sentimientos que debieran ser purificados mediante «temor» 0 "piedad» no tiene cabida ante el crecimiento de violencia machista, los feminicidios, la feminización de la pobreza, la ruptura del estado de bienestar y la pujante amenaza de la derecha para el recorte de libertades. En dicho statu quo resulta relevante forjar una opinión crítica en la recepción interpelando al gran público, apelando a la necesidad de cambiar la realidad. En este sentido, la performance resulta de nuevo el artificio artístico más adecuado para dicho propósito. Si bien una identificación plena podría ser posible en una élite que comparta las mismas intersecciones que la rapera, no es significativa para lograr una difusión internacional. Es por ello que este propósito social que motivó en el teatro la reformulación del mismo y la tendencia hacia un drama más épico (narrativo), nos resulta más convincente para mostrar cómo el rap feminista aboga por una performance que incita al auditorio a tomar partido.

Un ejemplo de distanciamiento lo encontramos en la recepción que tuvo la canción «Mami que voy pa'la mani» (Gata Cattana, 2015), una crítica aguda contra la menguada libertad de expresión tras la entrada en vigor de la conocida popularmente como «ley mordaza», que la artista asocia con la represión franquista en España:

\footnotetext{
Los hijos que no tendremos

porque falló la memoria

y se repite la historia

siempre caen los buenos

y cunde la fobia
} 
(...)

Mami que ya no se acuerdan

del tiempo de mis abuelos,

que obrero que se levanta

lo llevan al matadero.

Pese a que la canción la inspira un acontecimiento nacional, la represión franquista, ${ }^{21}$ su temática universal, así como la autenticidad y pureza del sentimiento, la han consolidado como símbolo de la dictadura, himno contra la censura, como observamos en el visionado de las distintas reelaboraciones que su público ha hecho de la canción: los montajes con imágenes de conflictos bélicos latinoamericanos para denunciar la represión civil tematizando la violencia verbal y física como un lastre global; o los panfletos y carteles de las manifestaciones con pasajes de sus canciones, mensajes ritualizados como himnos feministas, cuyo origen se va perdiendo, como el conocido «Un tributo a mis musas, que luchan», procedente de la canción «Lisístrata» que encontramos en manifestaciones de distintos contextos, siendo la primera de ella la multitudinaria del 8M de 2018 en Madrid.

De este modo, encontraría en la crítica, muchas veces simplemente descriptiva, las consecuencias del patriarcado y podría así tomar una actitud comprometida con su realidad social. Esta es la recepción internacional de su obra, que interpela a las mujeres a través de los ejes de género y violencias explícitas y simbólicas por el hecho de ser mujer, pero que también busca la atención de los hombres a los que se dirige a veces de modo intradiegético, como observamos en esta dicotomía entre ellas, representadas como dos criaturas mitológicas empoderadas frente a los potenciales enemigos, portavoces concretos del sistema simbólico abstracto: «Tú y cuántos como tú contra estas dos titánides» (Gata Cattana, «Lisístrata», 2015).

De este modo, al igual que existen interpelaciones directas a la recepción masculina, a la artista le interesa llamar la atención en aquellas mujeres subalternas con las que no comparte rasgos factuales, pero que son sus narratarias en la esfera ficcional, como expresa en «El Plan» (Banzai, 2017):

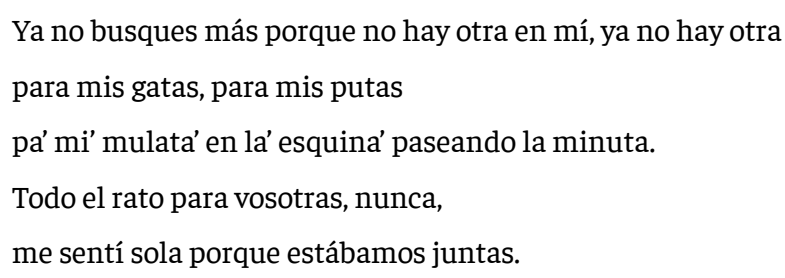

Además de la performance con pretensiones de sororidad y las colaboraciones entre raperas con distintas idiosincrasias, ${ }^{22}$ otro recurso para fomentar el distanciamiento en el rap se encuentra en los scratches y la intertextualidad producida mediante el sampleado, ${ }^{23}$ es decir, a través de la inclusión de fragmentos que nos recuerdan a que lo que se escucha es una obra de arte y no la realidad factual. Dichos constructos funcionan en este caso como interrupciones intencionadas para romper la «identificación» o impedir la catarsis; y, además, desde el universo creativo de las autoras, se insiste en que los elementos que se introducen de la realidad no son las opiniones de las raperas, sino hechos con un fundamento en el mundo exterior no ficcional. 


\section{Conclusiones}

El rap de Gata Cattana nos invita a indagar en la construcción de identidades que se articulan por medio de su mensaje y sus actantes; pero también supone un planteamiento teórico en lo que subyace al rap como género cultural que se nutre de la literatura. El carácter performativo del logos se traduce en la expresión y construcción de una identidad que recorre las intersecciones de las raperas que enuncian a través del rap feminista, discurso que emplea recursos artísticos como la performance, pero que acude a la factualidad en tanto que pretende en última instancia un cambio en el statu quo. Estas subjetividades emplearán el rap con dos propósitos: una pulsión existencialista, ligada al efecto catártico de la literatura, es decir, el proceso profiláctico que lleva implícita la composición y consumo del rap conciencia; pero también a una necesidad sociopolítica de cambio, a través de la puesta en marcha de mecanismos de protesta para afrontar la injusticia participando como actante.

La autora determina su politropía gracias a las dimensiones que constituyen su performance. La artista se convierte así en la periodista, la activista y en la oradora pública, portadora del saber de sus antepasadas en la "ceremonia del rap», empleando para este trabajo una de las lecturas de la performance que más potencial transformador supone: la performance como «acción». En su herencia literaria, el rap feminista se nutrirá de la dramaturgia en dos sentidos: aplicando procedimientos teatrales (catarsis y efecto de distanciamiento), pero también renovando el campo teatral al brindar nuevos perfiles para el coro. En este sentido, comprendemos el acto performativo (la ejecución o la realización del rap) como un fenómeno de ritual en el que la rapera es la protagonista, cuya función estética arroja interpretaciones textuales de índole antropológica y asemeja su proceso de composición al de la literatura, así como su puesta en escena. Además, comprendemos el rap como catalizador del descontento social e instrumento de transformación mediante el estudio de su performance lingüística, ya que su componente referencial y realizativo reside en la intención de la autora, quien parece alentarnos a contemplar una hipótesis más optimista, en la que el acto vocal de rapear se vuelve performativo ya que al pronunciar las palabras se producen cambios sustanciales en el mundo.

En definitiva, la crítica y el público está consagrando la obra y figura de Gata Cattana a través de la reelaboración de su música, poesía e imagen del feminismo a niveles nacionales e internacionales operando sobre un aparato ideológico y un imaginario del rap desde la memoria histórico-literaria, corrigiendo el lastre patriarcal que impedía sus aportaciones. Su trayectoria, hecha símbolo, se expresa —a través de numerosos festivales feministas, documentales, exposiciones fotográficas y menciones intertextuales dentro y fuera del rap — retroalimentando la obra de sus coetáneos y llegando a ocupar un lugar en la memoria colectiva como rapera, como poeta y como referente del feminismo interseccional y del feminismo andaluz.

\section{Notas}

1 Entendemos este término en su definición posestructuralista como el significante discursivo que proyecta en las obras de arte las connotaciones ideológicas de una determinada conciencia o sentir social (la conciencia colectiva) para ponerlas en circulación y difundirlas a través de la literatura.
$2 \mathrm{Al}$ igual que la dimensión sociocultural del rap ha de ser analizada a través de la interseccionalidad, tampoco pueden desvincularse los aspectos literarios de los retóricos. Un ejemplo de dicha conexión la encontramos en el estudio etimológico de la palabra «hypokrítiké [téchne]», la noción clásica de 
performance, que se fundamentaba en la técnica teatral como el modo de exponer y de gesticular (valores fónicos, mímicos y gestuales). Este término no solo figura en la Retórica sino también en la Poética de Aristóteles bajo el término «hypocrisis» (recitación teatral del poema) (Garavelli, 1991). Su noción como «licencia poética» resulta aplicable a ambas materias y permite un análisis del rap como discurso que las integra.

3 Además de la negativa opinión general del público lego en la materia, la crítica ha subestimado a menudo el potencial de este estilo musical para acceder a un terreno político a través del arte. Algunos de los prejuicios infundados sobre el rap atañen a la materialización de la misoginia a través de una hipersexualización de las bailarinas en los videoclips y unas letras sexistas, reduciendo el rap a la obra de raperos del mainstream (generalmente de la subcorriente gangsta-rap) y obviando la producción tanto de mujeres activas en esta materia y como de ciertos raperos comprometidos con el feminismo interseccional. Otro factor de desinterés para los estudios académicos respecto al rap se sitúa en la posición periférica que ha ocupado en materias como la musicología o la crítica literaria, que se han servido de él como recurso anecdótico o ejemplificador de algún aspecto más interesante para el canon, devaluando así su potencial como género propio.

$4 \mathrm{Si}$ bien es cierto que la performatividad del hip hop como realización corporal se hace más evidente en la puesta en escena del elenco de breakdancers, el acto de protesta de pintar edificios públicos o vagones que conlleva el graffiti o la fuerza realizativa en el mensaje y actitud de los raperos nos obliga a considerar también la pintura y la música como elementos de acción transformadores, y, por ende, como productos culturales dignos de ser analizados desde una dimensión performativa.

5 La convicción de Gata Cattana sobre la utilidad de su poesía aparece en diversas entrevistas y es un leitmotiv de su obra: la poesía y más aún el rap debían ser «el arma», empleando un vocabulario bélico que la misma autora elige para acabar con el patriarcado. En este sentido, resulta evidente el impacto real que la autora pretendía con su obra, más allá del legado ficcional que reservaba para la poesía, plasmada primero en su blog y luego en el poemario que publicó en vida: La escala de Mohs (2016).

6 Ramírez Torres señala como elementos performativos: «la agilidad de sus versos, su flow, sus movimientos y la actuación en el escenario y las expresiones con las que se dirigen a su audiencia» (2017:225).
7 La solemnidad de la ceremonia ha sido representada en el rap feminista a través del carácter ritual, fundamental para la creación de constructos simbólicos, entendidos también como «actividades caracterizadas por su repetición ad infinitum, independientemente de su propósito social» (Schechner, 2000:13). Por otra parte, el ritual es una suerte de ceremonia colectiva que indica a los participantes lo que tienen en común y lo que los une y conforma dentro de una comunidad compartida (en el caso del rap se produce los conciertos o free style battles en los que público y performers participan del evento empleando unos símbolos que los vinculan como comunidad representante de su «tribu urbana»).

$8 \mathrm{Al}$ contrario de lo que pasa en otros estilos musicales, cuya performance comparten un grupo de músicos y en cuyo trabajo reside el producto total, en el rap la dicción del rapero va acompañada por su desempeño individual. Incluso en las colaboraciones no suele ocurrir que dos o más raperos canten a la vez, sino que se establece un orden lineal de aparición en escena, como se acostumbra en el teatro cuando se produce un soliloquio. Así pues, a cada «personaje» le corresponde una dicción y un estamento. Por ello, no hay tendencia a la agrupación, sino que cada artista tiene a disposición un espacio en el que defender su postura. Dichos elementos quinésicos presentes en las batallas de rap mantienen afinidades con el teatro, como el hecho de que se rapee sobre un escenario buscando una interacción con el público, elemento que sitúa al rap en un plano cercano con el teatro experimental; pero también con la oratoria, en tanto que la rapera argumenta ante un auditorio para ganarse su apoyo.

9 La propia rapera lo expresaba así en su última entrevista: «Gata Cattana es una chica con los ojos muy abiertos y que no deja de rebelarse contra la mezquindad del hombre y la injusticia. Es el alter ego de Ana Sforza, la autora, la poeta, la parte más sensible y calmada de todo esto... Gata Cattana es el personaje, una heroína de ficción casi, la faceta más guerrera, punky y directa. Digamos que Ana, en tanto que humana, tiene muchas debilidades, pero Gata Cattana es invencible» (García Llorente).

10 Observamos cómo el rap cumple todas las funciones que desempeñaba el coro en la tragedia clásica. A parte de su carácter demarcador, ritual y narrativo, destaca su función mediadora, que ponía en relación la acción representada en escena con el público, a través de la interpretación de lo que 
sucedía (Estébanez Calderón, 2001:217). El coro, que es la voz de la autora en el rap, muestra así su vindicación política, al dirigir la interpretación de los hechos hacia una lectura feminista, que no procede de la imaginación individual de la autora sino del imaginario colectivo contracultural de la historia del feminismo.

11 Este carácter monótono del beat confiere al rap un estado de trance apropiado para la interpretación cognitiva de su mensaje. Así pues, la base instrumental y lingüística de la autora serán elementos fundamentales para inducir la catarsis o el distanciamiento con la obra de arte.

12 La elección del beat no solo tiene implicaciones válidas para redirigir la recepción, sino que va condicionada por los propios gustos de la artista, temática de los textos y productores con los que trabajó durante su carrera. De este modo, el rap es un producto multiautoral que no depende enteramente de la rapera (MC).

13 Para un análisis más profuso de esta canción véase Pinilla (2020).

14 Me refiero a uno de los numerosos proyectos que protagoniza la activista y periodista independiente Barbijaputa. El inicio de la canción «Lisístrata» funciona como el marco para reconocer esta sección. Se ha convertido en leitmotiv del podcast. Es una muestra más de la consagración de Gata Cattana como una representante del feminismo no hegemónico.

15 Resulta un rasgo indispensable, cuyo opuesto en la dicotomía es lo fake (falso). Otras corrientes más actuales como el trap emplean este mismo término, en su versión hispanizada: «feka».

16 Esta canción es uno de los mejores ejemplos de texto de rap en el que abundan todos los registros y usos de la lengua. Destacan cultismos (modus operandi) que coexisten en un mismo discurso con vulgarismos («follo», «me cago en tó"», "putas»), coloquialismos («la Ana», «os lo tengo dicho»), voces de la jerga juvenil (raya'os, rollo punki) o de la jerga del rap (make it rain) y gitanismos (camelo), junto con referencias de actualidad política o cultura (discriminación positiva, Teoría King Kong, etc).

17 En cuanto a esto, la rapera estaría experimentando una etapa de «crisis» (Turner, 1987) o fase del umbral en la que se ha desprovisto de su condición de subalterna y va asimilando, en la fase correctiva, las pautas de conducta de su nuevo estatus hasta por fin formar parte de una suerte de reintegración en la nueva clase y reconocimiento de los miembros del gremio. Este cambio de estatus viene ligado a las características intrínsecas del rap como movimiento social, no solo por la conexión temática entre el rap y el anhelo de salir de la subalternidad que movía a los jóvenes marginados a buscar en este estilo musical una oportunidad para prosperar en el sentido de mejorar sus condiciones sociales, sino más bien porque el rap se ha considerado siempre «un mundo de hombres», de modo que un rap feminista buscaría además de la mejora social la construcción de una identidad válida y poderosa en una escena en la que las mujeres encuentran obstáculos para ostentar poder y tener representación.

18 A propósito del uso del acento andaluz que observamos en todo su rap, su biografía ofrece luz a la interpretación de algunos de sus versos. Estando en Madrid y habiendo experimentado, posiblemente, el estigma, destaca su propia reflexión con la que se niega a la imposición de un dialecto estándar hegemónico en los círculos cultos de la ciudad como medida de integración que la artista afronta como una «pérdida de identidad»: «Someto mi fonética a ese examen inútil, estúpido como las manis, siempre hay quien es "bien" y quien es mal y (...)» («Al Norte», 2013).

19 Rapero alicantino referente a nivel mundial del rap en español. Destaca su peculiar estilo para rapear, los contenidos existenciales y sociales, así como su magistral dominio de la palabra.

20 Un planteamiento de la música con fines utilitaristas contemplaría la literatura como artefacto agitador de conciencias volcado en la imposición de un determinado aparato ideológico (Asensi, 2007). Si bien la ideología de género se construye también desde distintos estilos musicales, tanto por su recepción juvenil como la cantidad y calidad de las producciones, deberíamos considerar al rap como el género musical en el que más se está trabajando para erradicar la violencia patriarcal en nuestros días.

21 Algunas versiones en memoria de Gata Cattana son las que tienen fines más catárticos. Destaca a este respecto la que realizó su propia madre en compañía de su círculo de Granada, donde estaban algunas de las grandes promesas del rap andaluz actual, como los influyentes gemelos Ayax y Prok, quienes dedican un verso a la artista en el primer aniversario de su muerte: «Mi Cattana no maúlla,/ está durmiendo, (...)» (Ayax, "Cosa mía»-2018-).

22 La lectura de un feminismo interseccional universal se materializa en las numerosas colaboraciones entre raperas 
de distintas culturas e idiomas a fin de reivindicar la lucha feminista.

23 Un ejemplo representativo que rompe la catarsis se encuentra en la incursión del discurso político de la asambleísta ecuatoriana Rosana Alvarado en la canción «Lisístrata». Esta voz en off introduce la grabación de un discurso no artístico que tematiza las nefastas consecuencias de la religión y el patriarcado sobre la mujer. El uso del sampleado en esta canción demuestra cómo «lo personal es político» trazando una línea entre la situación de la mujer en la Biblia, en la sociedad ecuatoriana, en la sociedad española y en todas las épocas y momentos de la historia.

\section{Referencias}

\section{Primaria}

Gata Cattana (2017). El plan. Banzai. Fundación Gata Cattana. CD.

Gata Cattana (2015). Lisístrata. Anclas. Madrid, España: La Cucaracha Estudios. EP.

Gata Cattana (2015). La prueba. Anclas. Madrid, España: La Cucaracha Estudios. EP.

Gata Cattana (2016). Rayos. Inéditos 2015. Madrid, España: La Cucaracha Estudios. EP

Gata Cattana (2016). Yerma. Lancashire, Reino Unido: White Noise. Track.

Gata Cattana (2016). Mami que voy $p a^{\prime}$ la mani. Archivo de video. https://www.youtube.com/ watch?v=1uyhKTPCczs

\section{Secundaria}

Asensi, M. (2007). Crítica, sabotaje y subalternidad. Lectora, (13), 133-153. https://revistes.ub.edu/index.php/ lectora/article/view/7405

Avenburg, K. y Martínez, B. (2014). Experiencias e interpretaciones en performances rituales: Iruya y El Cajón (noroeste argentino). Cuadernos de Antropología social, (39), 115-147.

Austin, J.L. (1982). Cómo hacer cosas con palabras. Barcelona, España: Planeta.

Barbijaputa (2020). Radiojaputa. El postcast feminista radical de Barbijaputa. https://radiojaputa.com/

Benjamin, W. (1975). ¿Qué es el teatro épico? Tentativas sobre Brecht. Iluminaciones III. Madrid, España: Taurus.

Bruner, J. (1986). Realidad mental y mundos posibles. Los actos de la imaginación que dan sentido a la experiencia. Barcelona, España: Gedisa.

Buscató Vásquez, A. (2016). Las figuras retóricas en el rap español del siglo XXI. Madrid, España: Adarve.

Camargo, L. (2007). De la protesta a la cesta: resistencia y mercantilización en la escena del rap. Viento Sur, (91), 50-58. https://cdn.vientosur.info/VScompletos/vientosurg1-plural-culturasalacontra-lauracamargo.pdf

Chang, J. (2007). Can't Stop Won't Stop: A History of the Hip-Hop Generation. Nueva York, EE. UU.: St. Martin's Press.

Checa Puerta, J.E. (2012). La escena madrileña de la última década. Don Galán: revista de investigación teatral, (2), 27-31.

Corral Rogríguez, A. (2014-2015). Empoderamiento en el hip hop femenino español: una aproximación desde los Estudios de Género y Semiótica al rap maistream. Tesis doctoral. Universitát Pompeu Fabra, España.

El Chojin (2020). Pero de buen rollo. Youtube. https://www.youtube.com/watch?v=3n88DciKW5I

Estébanez Calderón, D. (2001). Diccionario de términos literarios. Madrid, España: Alianza Editorial.

Federici, S. (2009). Caliban and the Witch. Brooklyn, EE. UU.: Autonomedia.

Garavelli, B.M.(1991). Manual de retórica. Madrid, España: Cátedra. 
García Llorente, A. (2017). La última entrevista a Gata Cattana: «Ana tiene muchas debilidades pero Gata Cattana es invencible»./Entrevistada por Guillermina Torresi. La Vanguardia. https://www.lavanguardia.com/demoda/20170302/42476395351/gata-cattana-rapera-poetisa-entrevista.html

Haraway, D. (1991). Manifiesto para ciborgs: ciencia, tecnología y feminismo socialista a finales del siblo XX. Ciencia, cyborgs y mujeres. La reinvención de la naturaleza. Madrid, España: Cátedra.

Hodges Persley, N. (2015). Hip-hop theater and performance. En Williams, J. (Ed.). The Cambridge Companion to Hip-Hop (85-98). Cambridge, Reino Unido: Cambrige University Press.

Lanser, S. (1992). The narrative act: point of view in Prose Fiction. Princeton, EE. UU.: Princeton University Press.

Martínez Cantón, C.I. (2010). Innovaciones en la rima: poesía y rap. Rhytmica, (8), 67-94. http://revistas. uned.es/index.php/rhythmica/article/view/13095/12074

Millet, K. (1970). Política sexual. Nueva York: Doubleday.

Moore, J.W. (2014). The capitalocene. Part I: On the nature \& origins of our ecological crisis. Binghampton, EE. UU.: Binghampton University.

Kautny, O. (2015). The Analysis of Linguistical and Rhythmical Aspects of Rap. En Williams, J. (Ed.). The Cambridge Companion to Hip-Hop (99-117). Cambrige University Press.

Pinilla Alba, S. (2020). Identidad y disidencia sexual en el rap feminista queer: un análisis narratológico de «Lisístrata», de Gata Cattana. Descentrada, 4(2). https://www.descentrada.fahce.unlp.edu.ar/article/view/ DESe118

Price-Styles, A. (2015). MC origins, rap and spoken word poetry. En Williams, J. (Ed.). The Cambridge Companion to Hip-Hop (11-21). Cambrige University Press.

Ramírez Torres, L. (2017). Cuando decir es hacer: el rap de mujeres en Bogotá como un acto performativo, Encuentros, 15(3), 225-240.

Reyes Sánchez, F. (2007). Hip hop, graffiti, break, rap, jóvenes y cultura urbana. Revista de Estudios de Juventud, (Culturas y lenguajes juveniles), (78), 125-139.

Romera Castillo, J. (2016). Teatro y música en los inicios del siglo XXI. Madrid, España: Verbum.

Salgado Rógerio, M. (2015). Entre ritmo e poesia: rap e literatura oral urbana. Scripta, 19(37), 153-165. https:// www.academia.edu/26753683 Entre_ritmo_e_poesia_rap_e_literatura_oral_urbana7

Schechner, R. (2000). Performance. Teoría y prácticas interculturales. Buenos Aires, Argentina: Libros de Rojas.

Spivak, G.C. (2009). Can the Subaltern speak? Asensi Pérez, M. (Ed.) ¿Pueden hablar los subalternos? Barcelona, España: MACBA. Traducido por Asensi Pérez, M.

Turner, V. (1987). The Anthropology of Perfomance. En The Anthropology of Performance, (1-36). Nueva York, EE. UU.: PAJ Publications.

Van Dijk, T.A. (1999). El análisis crítico del discurso. Anthropos (189), 23-36. 